\title{
Real-world Evidence for the Antianginal Efficacy of Trimetazidine from the Russian Observational CHOICE-2 Study
}

\author{
Maria Glezer · On behalf of the CHOICE-2 study investigators
}

Received: October 21, 2016 / Published online: February 20, 2017

(C) The Author(s) 2017. This article is published with open access at Springerlink.com

\begin{abstract}
Introduction: The guidelines recommend a beta-blocker or calcium channel blocker as the first-line medication for angina, supplemented by other agents for additional symptoms. One such agent is trimetazidine (TMZ), which has been shown to reduce the frequency of anginal episodes and improve exercise performance without affecting haemodynamic parameters. However, extensive real-world evidence for its efficacy in combination with first-line therapies has been lacking.
\end{abstract}

Methods: The aim of this large-scale, Russian, multicentre, 6-month, open-label, prospective observational study was to assess the effect of adding TMZ modified release $35 \mathrm{mg}$ bid to background antianginal therapy in the real-world clinical setting.

Results: The study included 896 patients: 54\% women, aged $29-90$ years $(42.6 \%>65$ years), $63 \%$ with class II angina, and receiving beta-blockers alone or in combination (93\%). Add-on TMZ reduced angina frequency and

Enhanced content To view enhanced content for this article go to http://www.medengine.com/Redeem/3A87 F06042A09B59.

M. Glezer $(\bowtie)$

Department of Preventive and Emergency

Cardiology, Sechenov First Moscow State Medical

University, Moscow, Russia

e-mail: 287ast@mail.ru short-acting nitrate use within 2 weeks (both $p<0.0001)$ regardless of background therapy and maintained this effect over 6 months. It increased the proportion of patients with class I angina sixfold while decreasing that of class 3 angina almost fourfold. It also improved walking distance and well-being at 6 months (both $p<0.0001)$. Treatment was well tolerated.

Conclusion: Add-on TMZ is a safe and rapidly effective treatment for reducing angina attacks and nitrate use in the real-world clinical setting. It also increases exercise capacity and well-being. These effects are observed within 2 weeks and persist for at least 6 months.

Keywords: Antianginal combination therapy; Beta-blocker treatment; Clinical practice; Observational study; Real-world evidence; Stable angina; Trimetazidine

\section{INTRODUCTION}

Angina is the cardinal symptom of coronary artery disease (CAD), the associated disability, morbidity and mortality of which $[1,2]$ significantly impair quality of life [3-5]. Patients with stable angina have high rates of chest pain requiring hospitalisation and resource utilisation $[6,7]$. Any increased incidence of angina is associated with higher hospitalisation rates. Angina is also associated with an increased risk of major adverse cardiovascular event (MACE) 
outcomes (cardiovascular mortality, hospitalisation for myocardial infarction, heart failure or stroke) [8].

Drugs are the mainstay treatment, playing a fundamental role in preventing risk, relieving pain, reducing attack frequency and improving quality of life. Evidence-based management is crucial [9] and supports the option of multi-drug therapy [10]: in the prospective Euro Heart Survey most patients (59\%) received two or more antianginal drugs [11]. The evidence also shows that improved therapeutic strategies are needed. One reason is that as CAD patients increase in age and number, so angina prevalence increases with age [12]. Another reason is that even strategies based on current optimal, multiple, evidence-based medical therapy with or without revascularisation may fail to reduce MACE outcomes or eliminate angina: up to $40 \%$ of patients in the COURAGE trial experienced recurrent angina despite the different strategies applied [4].

Current guidelines state "Optimal medical treatment indicates at least one drug for angina/ ischaemia relief plus drugs for event prevention" and recommend beta-blocker monotherapy or beta-blocker and dihydropyridine calcium channel blocker combination therapy as the first-line medication for reducing angina/ ischaemia severity; various other agents may be considered for improving additional symptoms [10].

Trimetazidine (TMZ) is cytoprotective during ischaemia and thus indicated in the long-term treatment of stable angina. Its effects complement those of haemodynamically active agents. It reduces the frequency of anginal episodes and improves exercise performance without affecting haemodynamic parameters [13, 14]. Cardioprotection [15-18] has been demonstrated in both animal models [19, 20] and patients, whether with CAD $[14,21-24]$ or heart failure [25-28]. TMZ acts by optimising ATP production directly at the cardiac cell level and opposing ischaemic change [16].

The different mechanisms of action of anti-ischaemic drugs permit personalised treatments tailored to comorbidity and cardiac function [9]. Certain drug combinations may thus prove additive or even synergistic.
CHOICE-2 was designed to assess the impact over 6 months of adding TMZ modified release (MR) $35 \mathrm{mg}$ bid to background antianginal therapy in the real-world clinical setting.

\section{METHODS}

CHOICE-2 was a 6-month non-interventional, multicentre, open-label, prospective observational study conducted in Russia from September 2014 to September 2015 in a real-world clinical setting. Diagnosis, treatment and monitoring were exclusively physician-led, determined by the indications and contraindications of the medicinal products at the disposal of the general practitioner or cardiologist concerned. From inclusion onwards, physicians were free to modify treatment in the light of their own expertise and established clinical practice. Inclusion was decided solely by physicians according to the medical merit and necessity of treatment with TMZ $35 \mathrm{mg}$ bid.

The inclusion criteria were men and women $>18$ years of age providing their informed consent, with $\mathrm{a} \geq 3$-month history of stable angina documented by ECG-confirmed myocardial ischaemia and/or prior myocardial infarction, revascularisation or $>50 \%$ coronary stenosis, and treated for CAD in the past month. Non-inclusion criteria were: Canadian Cardiovascular Society (CCS) class 4 stable angina; hospitalisation in the past 3 months for acute coronary syndrome (infarction or unstable angina); uncontrolled hypertension (systolic $>180 \mathrm{mmHg}$ or diastolic $>100 \mathrm{mmHg}$ ) despite ongoing antihypertensive treatment; New York Heart Association (NYHA) class III or IV heart failure; pregnancy or breast feeding; CAD surgery scheduled in the next 6 months; severe hepatic or renal failure, or other severe chronic disease requiring continuous treatment; known poor treatment compliance; intolerance or contraindications to TMZ.

The protocol stipulated five visits: inclusion, week 2 (W2) and months 2, 4 and 6 (M2, M4, M6). At inclusion, eligible patients were informed about the study and TMZ and asked to provide their written consent. Case report forms (CRFs) were completed with the following data: 
general and cardiovascular history, cardiovascular risk factors, concomitant diseases, concomitant medication, heart rate, blood pressure, number of anginal attacks in the preceding week and short-acting nitrate consumption. Patients were assigned a CCS [29] and NYHA [30] class, exercise tolerance was measured by the walking distance eliciting angina, and well-being on a visual analog scale (VAS) graded 0-100 (maximal well-being). Investigators maintained the CRFs throughout treatment.

\section{Compliance with Ethics Guidelines}

All procedures complied with the ethical standards of the responsible committee on human experimentation (institutional and national), the Helsinki Declaration of 1964, as revised in 2013, and the European Independent Ethics Committee. The CHOICE-2 protocol was approved by the Inter-University Ethics Committee (protocol no. 09-14 dd. 23/10/2014; Moscow), and informed consent to inclusion in the study was obtained from all patients.

\section{Statistical Analysis}

Descriptive statistics were used for data analysis: mean, standard deviation (SD), range and median for normally distributed continuous variables and mean, SD, range, median and first and third quartiles for non-normally distributed continuous variables.

For qualitative and quantitative variables having few possible values, we calculated the absolute and relative incidences of each possible value. We compared quantitative variables before and after treatment within the same population or group using Student's $t$ test for normally distributed paired samples and Wilcoxon's test for non-normally distributed variables. To compare two study groups we used Student's $t$ test for independent samples in case of normally distributed quantitative variables and the Mann-Whitney test for non-normally distributed quantitative variables; we used the $\chi^{2}$ test for qualitative parameters. All tests were two-sided with a significance level of 0.05 .

\section{RESULTS}

\section{Population}

896 patients with stable angina were enrolled by 185 doctors from 46 regions of the Russian Federation; $35.5 \%$ were visiting the study physician for the first time, 59.5\% were already the physician's patients, and approximately $4 \%$ did not answer. Demographic and baseline clinical characteristics (Table 1) showed a majority of women (54\%) and an age range from 29 to 90 years, with a high proportion of elderly $(42.6 \%>65$ years). Most had hypertension; $70.1 \%$ had never smoked; $14 \%$ were former smokers. Only $16.3 \%$ had a normal body mass index; $44 \%$ were obese. CAD interventions, reported in $17.4 \%$, comprised percutaneous coronary intervention $(7.1 \%)$, coronary artery bypass grafting (5.0\%) and unspecified procedures $(6.2 \%)$. One patient in four had been hospitalised at least once in the past 6 months. Preventive medications comprised statins $(94 \%)$, angiotensin-converting enzyme inhibitors or angiotensin II receptor antagonists $(89 \%)$, aspirin (85\%) and clopidogrel (13\%).

Baseline antianginal treatments (Table 2) comprised beta-blocker monotherapy (45\%) and two-drug combination therapy (41\%); overall, $93 \%$ of patients were taking a betablocker alone or in combination. Only 23 patients (3\%) were not taking a beta-blocker, calcium channel blocker or long-acting nitrate, possibly because of intolerance or contraindications.

\section{Effect of TMZ 35 mg Add-on Therapy}

Over the 6 months angina frequency and short-acting nitrate use fell significantly (both $p<0.0001)$ from $5.36 \pm 5.38$ to $1.12 \pm 1.7$ attacks/week (Fig. 1a) and from $5.12 \pm 5.23$ to $0.87 \pm 1.43$ intakes/week (Fig. 1b). Both fell significantly from baseline within the first two treatment weeks.

The proportion of patients with class I angina increased sixfold (5-30\%), while that of class 3 angina decreased almost fourfold (27-7\%) (Fig. 2). Analysis with respect to 
Table 1 Demographics and baseline characteristics of the study population $(n=896)$

\begin{tabular}{|c|c|c|}
\hline & $\begin{array}{l}\text { Patients } \\
(n) \text { with } \\
\text { available data }\end{array}$ & \\
\hline Age, years $\pm S D$ & 861 & $64.0 \pm 9.4$ \\
\hline Gender, $n(\%)$ & 896 & \\
\hline Male & & $415(46.3)$ \\
\hline Female & & $481(53.7)$ \\
\hline $\begin{array}{l}\text { Body mass index } \mathrm{kg} / \\
\mathrm{m}^{2} \pm \mathrm{SD}\end{array}$ & 873 & $29.8 \pm 4.8$ \\
\hline \multicolumn{3}{|c|}{ Medical history and risk factors, $n(\%)$} \\
\hline $\begin{array}{l}\text { Previous myocardial } \\
\text { infarction }\end{array}$ & 896 & $309(35)$ \\
\hline $\begin{array}{l}\text { Previous } \\
\text { revascularisation }\end{array}$ & 896 & $156(17)$ \\
\hline Hypertension & 896 & $830(93)$ \\
\hline Diabetes & 896 & $186(21)$ \\
\hline Heart failure & 896 & $563(63)$ \\
\hline Current smoker & 890 & $137(15)$ \\
\hline Obesity & 873 & $394(44)$ \\
\hline $\begin{array}{l}\text { Patients with } \geq 1 \\
\text { hospitalisation during } \\
\text { previous } 6 \text { months }\end{array}$ & 896 & $232(26)$ \\
\hline \multicolumn{3}{|l|}{ Clinical parameters } \\
\hline $\begin{array}{l}\text { Angina attacks/ } \\
\text { week } \pm \text { SD }\end{array}$ & 896 & $5.36 \pm 5.38$ \\
\hline $\begin{array}{l}\text { Short-acting nitrate use/ } \\
\text { week } \pm \text { SD }\end{array}$ & 896 & $5.12 \pm 5.23$ \\
\hline $\begin{array}{l}\text { Systolic blood pressure, } \\
\mathrm{mmHg} \pm \mathrm{SD}\end{array}$ & 896 & $147.1 \pm 14.3$ \\
\hline Heart rate, bpm $\pm S D$ & 896 & $75 \pm 9.7$ \\
\hline $\begin{array}{l}\text { Canadian Cardiovascular } \\
\text { Society classification, } \\
n(\%)\end{array}$ & 845 & \\
\hline Class I & & $45(5)$ \\
\hline Class II & & $563(63)$ \\
\hline Class III & & $233(27)$ \\
\hline
\end{tabular}

Table 1 continued

\begin{tabular}{lll}
\hline & $\begin{array}{l}\text { Patients } \\
(\boldsymbol{n}) \text { with } \\
\text { available data }\end{array}$ & \\
\hline Class IV & $4(<1)$ \\
Medication, $n$ (\%) & 896 & $831(93)$ \\
Beta-blockers & $322(36)$ \\
Calcium channel & \\
blockers & $229(26)$ \\
Long-acting nitrates & $79(9)$ \\
Ivabradine & $547(61)$ \\
Angiotensin-converting & \\
enzyme inhibitors & $254(28)$ \\
Angiotensin II receptor & \\
antagonists & $844(94)$ \\
Statins & $764(85)$ \\
Aspirine & $117(13)$ \\
Clopidogrel & $483(54)$ \\
Diuretics &
\end{tabular}

first-line medication showed that TMZ significantly reduced weekly angina frequency independently of the physician's initial treatment (Fig. 3). Antianginal efficacy in other treatment groups comprising only a few patients (TMZ alone, TMZ combined with a calcium channel blocker or long-acting nitrate, and TMZ combined with two other antianginals) was similar and consistent with the main results (data not shown). Walking distance and well-being at 6 months increased significantly (both $p<0.0001$ ) from $336.9 \pm 252.9$ to $593.6 \pm$ $419.8 \mathrm{~m}$ (Fig. 4) and from $44.0 \pm 17.3$ to $77.3 \pm 16.6$ (Fig. 5).

Physicians adjusted antianginal treatments other than TMZ at least once during the study in $61 \%$ of patients. End of study heart rate was $65.8 \pm 6.1 \mathrm{bpm}$ and systolic blood pressure $127.4 \pm 9 \mathrm{mmHg}$. The antianginal effect of TMZ was independent of treatment adjustments, initial heart rate and systolic blood pressure. It was also consistent with results in the general study population (data not shown). 
Table 2 Antiangianal treatments at baseline

\begin{tabular}{lc}
\hline & Patients, $\boldsymbol{n}$ (\%) \\
\hline Medications & $896(100)$ \\
Monotherapy & $436(49)$ \\
BB & $403(45)$ \\
CCB & $22(3)$ \\
LAN & $11(1)$ \\
Two-drug combination & $365(41)$ \\
BB + CCB & $219(24)$ \\
BB + LAN & $137(15)$ \\
Other & $9(1)$ \\
Three-drug combination & \\
BB + CCB + LAN & $72(8)$ \\
Not BB, CCB or LAN & $23(3)$ \\
\hline
\end{tabular}

Some percentages do not add up to $100 \%$ because of rounding

$B B$ beta-blockers, $C C B$ calcium channel blockers, $L A N$ long-acting nitrates

\section{Tolerability}

A total of 881 patients completed the study per the protocol; 15 patients $(1.67 \%)$ discontinued treatment because of patient decision without explanation $(1.2 \%)$, death from stroke $(0.1 \%)$, hospitalisation for myocardial infarction (0.1\%) and other causes $(0.2 \%)$. Treatment was well tolerated and no related serious adverse events were reported.

\section{DISCUSSION}

While clinical trials remain the gold standard requirement for new drug registration, it is becoming increasingly apparent that the necessarily standardised, selective and artificial conditions under which they are conducted may provide little or no information on how a drug performs in the clinical practice setting. Real-world evidence gathered from post-approval observational studies has a crucial role to play in perfecting and personalising treatment
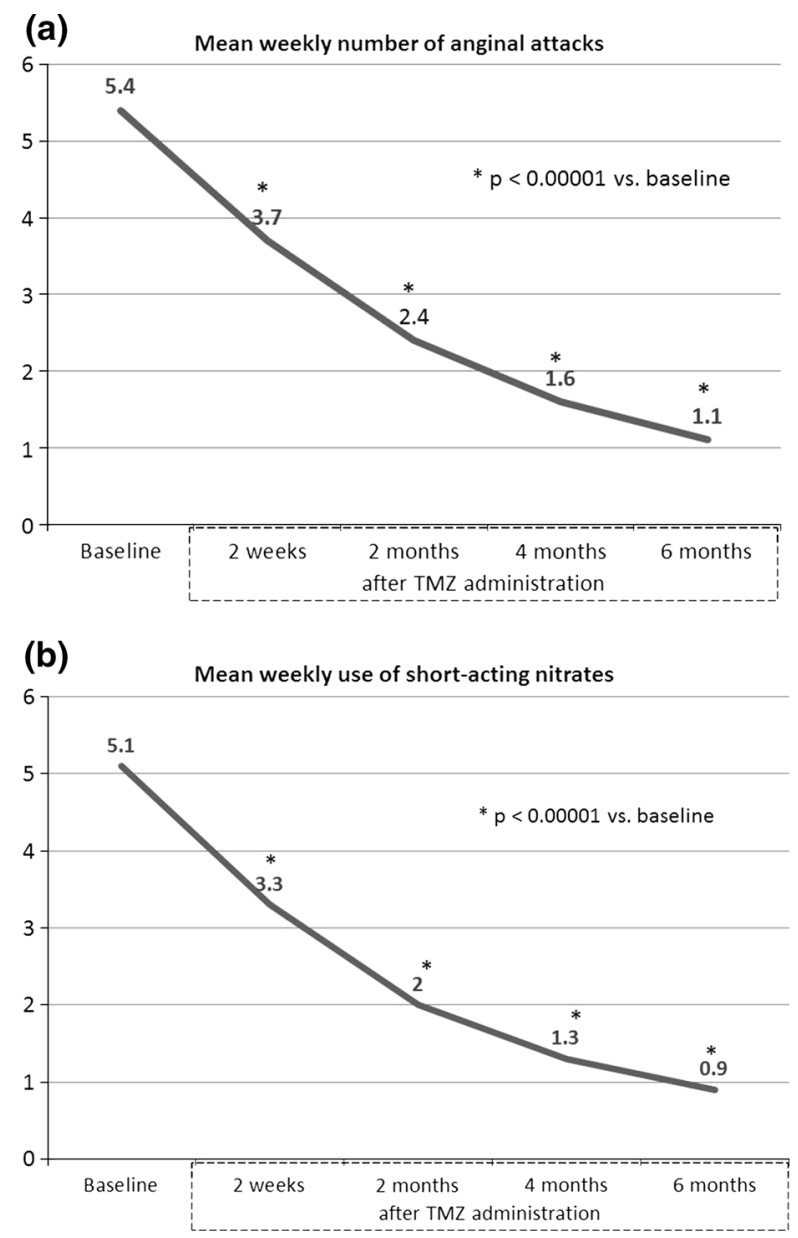

Fig. 1 Reduction in mean weekly angina attacks (a) and short-acting nitrate use (b) before and during trimetazidine administration; CLLS

delivery. Thus, a large-scale study such as CHOICE-2, conducted in the field, has provided powerful evidence of tangible additional benefits from TMZ: significant reductions in attack frequency and nitrate use, with significant increases in walking distance and quality of life.

Our study population was typical in that the treatments being received were in line with current recommendations: statins 94\%, beta-blockers $93 \%$, aspirin $85 \%$ and clopidogrel $13 \%$. Treatment profiles were consistent with those in recent observational studies of stable CAD [31]. The proportion of patients taking a combination of two or more antianginal drugs at inclusion (48\%) was similar to that reported by the Euro Heart Survey [11]. 


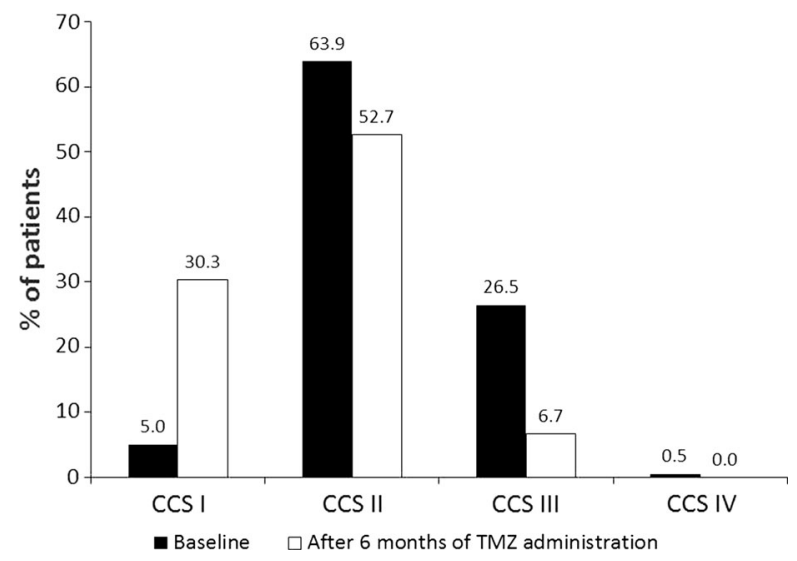

Fig. 2 Trimetazidine effect on change in CCS angina class at 6 months; CLLS

Most of our patients were in CCS class II and still experiencing angina despite correct treatment. Adding TMZ $35 \mathrm{mg}$ to their regimen was thus strictly in line with recommended management [10]. Efficacy proved significant within 2 weeks. To our knowledge, such early onset of action has not previously been reported. The effect increased with time in the overall population so that by 6 months it had reduced weekly angina attacks by $80 \%$. Efficacy was independent of ongoing background therapy in that it was consistent and comparable across treatment groups. The clinical relevance of this finding is that no additional effect is to be gained over that of the beta-blocker $+\mathrm{TMZ}$ combination by adding a calcium channel blocker or long-acting nitrate or both.

These results confirm those of the randomised clinical trials [14, 32-34] suggesting that the beta-blocker + TMZ combination be considered an optimal first-line approach to real-world angina. Thus the double-blind TRIMPOL-II (TRIMetazidine in POLand-II) study randomised 426 angina patients with documented CAD to TMZ $60 \mathrm{mg}$ daily or placebo in addition to first-line metoprolol $100 \mathrm{mg}$ daily [14]. Exercise testing, nitrate use, and angina frequency and intensity all showed significant improvement at 3 months versus baseline in the TMZ group compared to placebo.

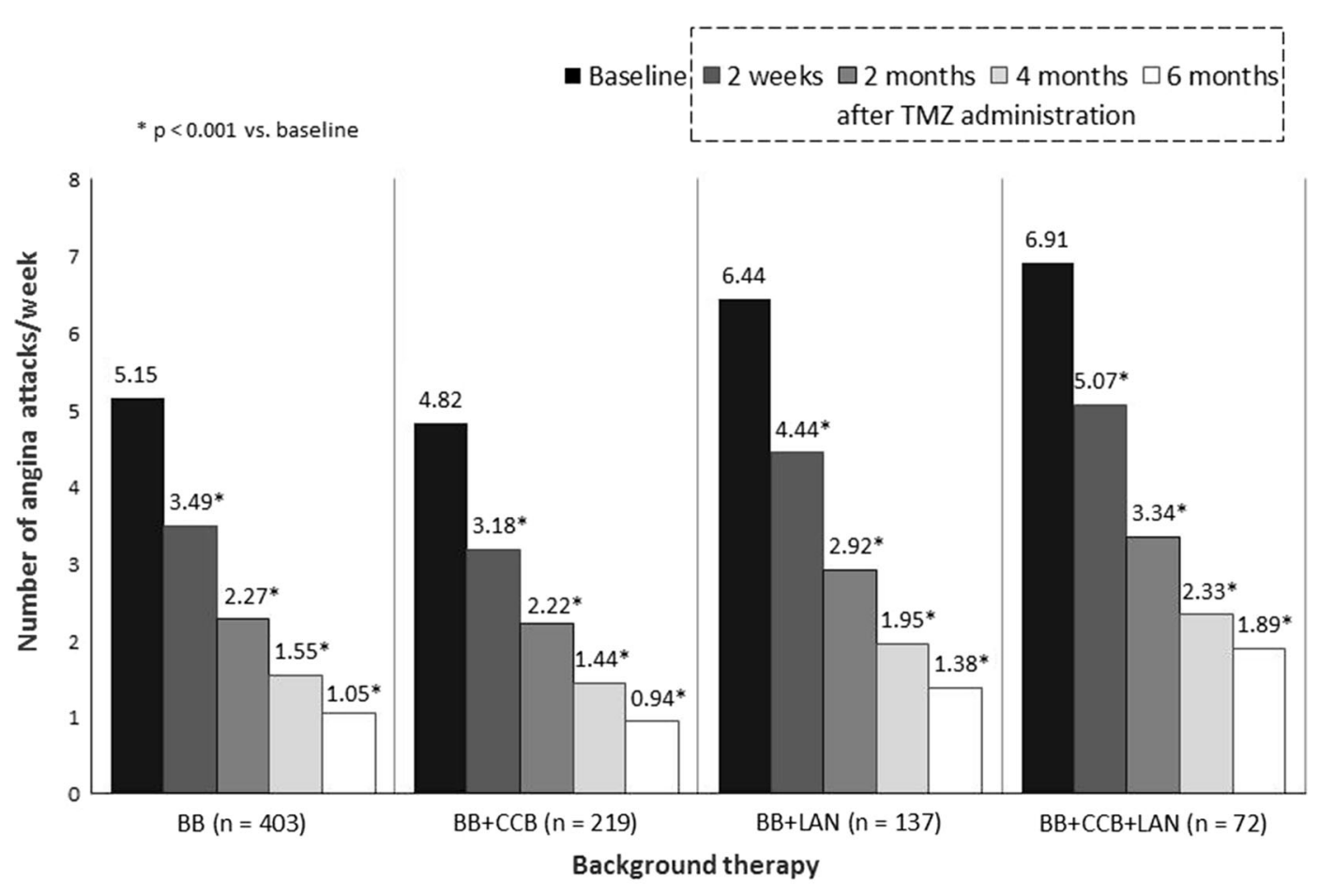

BB: Beta-blockers; CCB: Calcium channel blockers; LAN: Long-acting nitrates

Fig. 3 Angina attacks/week at baseline and after 2 weeks and 2, 4 and 6 months of trimetazidine administration in the four first-line therapy groups; CLLS 


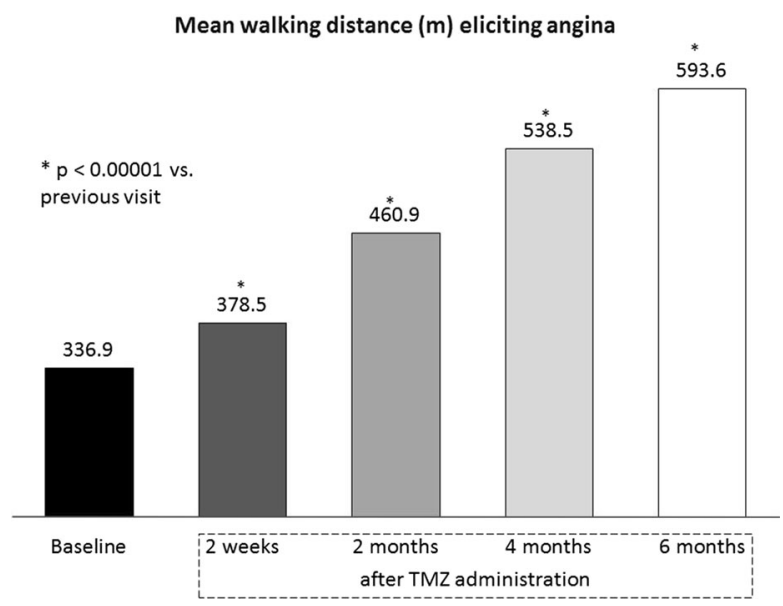

Fig. 4 Mean walking distance eliciting angina before and during trimetazidine administration; CLLS

Mean self-rated well-being

(visual analogue scale, 0-100)

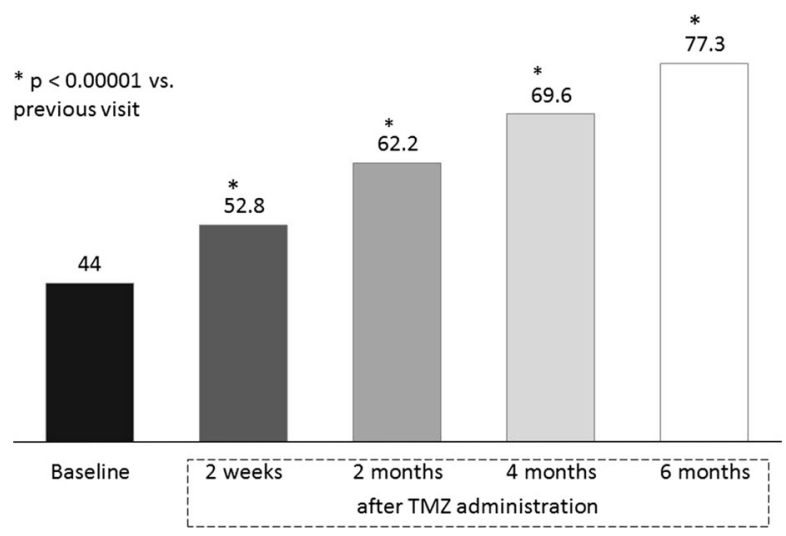

Fig. 5 Mean self-rated well-being (visual analogue scale, 0-100) before and during trimetazidine administration; (C)LLS

Another randomised double-blind study compared the addition of TMZ $60 \mathrm{mg}$ daily versus isosorbide dinitrate $30 \mathrm{mg}$ daily to first-line propranolol $120 \mathrm{mg}$ daily in 53 patients with angina inadequately controlled by the beta-blocker alone [35]. Reductions in attack frequency and nitrate use at 2 months were both greater in $\mathrm{TMZ}$ patients $(-63 \%$ and $-31 \%$, respectively). Moreover, exercise duration improved only in TMZ patients $(+14 \%$ vs. $2 \%$ with isosorbide dinitrate), as did time to 1-mm ST-segment depression (+15\% vs. $+3 \%)$. Overall, the study found TMZ a more effective antianginal than the long-acting nitrate.
A recent Ukrainian study added TMZ MR $35 \mathrm{mg}$ bid to the regimen of 1213 outpatients with angina inadequately controlled by standard beta-blocker therapy alone or combined with a long-acting nitrate or calcium channel blocker [36]. At 2 months TMZ significantly reduced weekly angina attacks from $6.4 \pm 0.1$ to $1.9 \pm 0.1$ and short-acting nitrate use from $5.7 \pm 0.1$ to $1.2 \pm 0.1$ (both $p<0.001$ ). Not only was a significant reduction in attack frequency seen in patients with more severe angina $(\geq 7$ angina attacks per week) regardless of first-line therapy, but maximal antianginal efficacy was achieved only with the dual combination of beta-blocker + TMZ.

Angina management has for years centred on the identification and removal of stenosis. However, extensive evidence strongly suggests that coronary artery obstruction is only one element in a complex multifactorial process leading to CAD. Obstructive lesions may be present but not necessarily causative [37]. Since stable ischaemic syndromes do not obligatorily require flow-limiting stenosis in a large coronary artery, and since severe stenosis does not necessarily cause all ischaemic syndromes, attention should rather focus on the microvasculature with attendant myocardial ischaemia and on the myocardial cell. Placing the myocardial cell at the centre of the model allows us to consider, and if possible pre-empt, all potential pathological inputs that might drive the progression of ischaemia to unstable angina, acute myocardial infarction, heart failure and sudden cardiac death.

TMZ acts directly at cell level by inhibiting long-chain 3-ketoacyl-CoA thiolase, a mitochondrial enzyme involved in fatty acid oxidation. Inhibition of this enzyme decreases fatty acid oxidation, which then stimulates glucose oxidation and inhibits glycolysis. These TMZ-induced chain effects increase the creatine phosphate/ATP ratio by a significant $33 \%$, indicating preservation of myocardial high-energy phosphate levels and ion pump function, which translates into improved cardiac efficiency and reduced symptoms [38]. These effects no doubt account for the real-world benefits our study has shown with add-on TMZ 
in the up to $40 \%$ of stable CAD patients with persistent angina.

\section{Study Limitations}

Despite the limitations inherent in its open-label, observational, non-interventional design, which may have introduced bias towards overestimation of treatment effect, this study provides important insights into the real-world management of stable angina. Strict inclusion criteria bar access to randomised controlled trials by the broader populations with multiple comorbidities and risk factors widely present in real-world practice. This may explain the elevated heart rate and systolic blood pressure at baseline. Other limitations to mention include the absence of a placebo group, which leaves unaddressed the question whether adding a placebo would have given the same results, and the absence of daily dose data for the various antianginals. A further limitation is that non-interventional trials may underestimate adverse events; these were not specifically sought but only evaluated in accordance with routine pharmacovigilance procedures.

\section{CONCLUSION}

The CHOICE-2 study shows add-on TMZ to be a rapidly effective strategy in the real-world clinical setting for reducing attack frequency and nitrate use in patients receiving first-line medication for stable angina. TMZ also increased walking distance and well-being. These effects were observed within 2 weeks and persisted for at least 6 months.

\section{ACKNOWLEDGEMENTS}

Sponsorship, article processing charges and the open access fee for this study were provided by Servier, Moscow, Russian Federation.

Editorial assistance and article processing charges were funded by Servier, France.
All named authors meet the International Committee of Medical Journal Editors (ICMJE) criteria for authorship for this manuscript, take responsibility for the integrity of the work as a whole and have given final approval for the version to be published.

All authors had full access to all of the data in this study and take complete responsibility for the integrity of the data and accuracy of the data analysis.

The authors would like to thank all participating investigators for their contribution to the study.

Disclosures. Maria Glezer received honoraria as scientific coordinator of this study and for lectures from "Servier", Moscow, Russian Federation.

Compliance with Ethics Guidelines. All procedures complied with the ethical standards of the responsible committee on human experimentation (institutional and national), the Helsinki Declaration of 1964, as revised in 2013, and the European Independent Ethics Committee. The CHOICE-2 protocol was approved by the Inter-University Ethics Committee (protocol no. 09-14 dd. 23/10/2014; Moscow), and informed consent to inclusion in the study was obtained from all patients.

Data Availability. The data sets analysed during the current study are available from the corresponding author on reasonable request.

Open Access. This article is distributed under the terms of the Creative Commons Attribution-NonCommercial 4.0 International License (http://creativecommons.org/licenses/ by-nc/4.0/), which permits any noncommercial use, distribution, and reproduction in any medium, provided you give appropriate credit to the original author(s) and the source, provide a link to the Creative Commons license, and indicate if changes were made. 


\section{REFERENCES}

1. Murray CJ, Lopez AD. Mortality by cause for eight regions of the world: Global Burden of Disease Study. Lancet. 1997;349(9061):1269-76.

2. Murray CJ, Lopez AD. Alternative projections of mortality and disability by cause 1990-2020: Global Burden of Disease Study. Lancet. 1997;349(9064): 1498-504.

3. Strauss WE, Fortin T, Hartigan P, Folland ED, Parisi AF. A comparison of quality of life scores in patients with angina pectoris after angioplasty compared with after medical therapy: outcomes of a randomized clinical trial. Circulation. 1995;92:1710-9.

4. Boden WE, O'Rourke RA, Teo KK, et al. Optimal medical therapy with or without PCI for stable coronary disease. $\mathrm{N}$ Engl J Med. 2007;356:1503-16.

5. Weintraub WS, Spertus JA, Kolm P, et al. Effect of PCI on quality of life in patients with stable coronary artery disease. N Engl J Med. 2008;359:677-87.

6. Poole-Wilson PA, Vokó Z, Kirwan BA, de Brouwer S, Dunselman PH, Lubsen J. Clinical course of isolated stable angina due to coronary heart disease. Eur Heart J. 2007;28:1928-35.

7. Povsic TJ, Broderick S, Anstrom KJ, et al. Predictors of long-term clinical endpoints in patients with refractory angina. J Am Heart Assoc. 2015;4:e001287.

8. Jespersen L, Hvelplund A, Abildstrøm SZ, et al. Stable angina pectoris with no obstructive coronary artery disease is associated with increased risks of major adverse cardiovascular events. Eur Heart J. 2012;33:734-44.

9. Husted SE, Ohman EM. Pharmacological and emerging therapies in the treatment of chronic angina. Lancet. 2015;386:691-701.

10. Montalescot G, Sechtem U, Achenbach S, et al. 2013 ESC guidelines on the management of stable coronary artery disease: the Task Force on the management of stable coronary artery disease of the European Society of Cardiology. Eur Heart J. 2013;34:2949-3003.

11. Daly CA, Clemens F, Sendon JL, et al. The initial management of stable angina in Europe, from the Euro Heart Survey A description of pharmacological management and revascularization strategies initiated within the first month of presentation to a cardiologist in the Euro Heart Survey of Stable Angina. Eur Heart J. 2005;26:1011-22.
12. Buckley BS, Simpson CR, McLernon DJ, Murphy AW, Hannaford PC. Five year prognosis in patients with angina identified in primary care: incident cohort study. BMJ. 2009;339:b3058.

13. Dalla-Volta S, Maraglino G, Della-Valentina P, Viena P, Desideri A. Comparison of trimetazidine with nifedipine in effort angina: a double-blind, crossover study. Cardiovasc Drugs Ther. 1990;4 (suppl 4):853-9.

14. Szwed H, Sadowski Z, Elikowski W, et al. Combination treatment in stable effort angina using trimetazidine and metoprolol: results of a randomized, double-blind, multicentre study (TRIMPOL II). TRIMetazidine in POLand. Eur Heart J. 2001;22:2267-74.

15. Cross HR. Trimetazidine for stable angina pectoris. Expert Opin Pharmacother. 2001;2:857-75.

16. Di Napoli P. Anti-ischemic cardioprotection with trimetazidine. Heart Metab. 2008;41:25-9.

17. Tsioufis K, Andrikopoulos G, Manolis A. Trimetazidine and cardioprotection: facts and perspectives. Angiology. 2015;66:204-10.

18. Dézsi CA. Trimetazidine in practice: review of the clinical and experimental evidence. Am J Ther. 2016;23:e871-9.

19. Dehina L, Vaillant F, Tabib A, et al. Trimetazidine demonstrated cardioprotective effects through mitochondrial pathway in a model of acute coronary ischemia. Naunyn Schmiedebergs Arch Pharmacol. 2013;386:205-15.

20. Wei J, Xu H, Shi L, Tong J, Zhang J. Trimetazidine protects cardiomyocytes against hypoxia-induced injury through ameliorates calcium homeostasis. Chem Biol Interact. 2015;236:47-56.

21. Detry JM, Sellier P, Pennaforte S, et al. Trimetazidine: a new concept in the treatment of angina. Comparison with propranolol in patients with stable angina. Trimetazidine European Multicenter Study Group. Br J Clin Pharmacol. 1994;37:279-88.

22. $\mathrm{Hu} \mathrm{B}, \mathrm{Li} \mathrm{W}, \mathrm{Xu} \mathrm{T}$, et al. Evaluation of trimetazidine in angina pectoris by echocardiography and radionuclide angiography: a meta-analysis of randomized, controlled trials. Clin Cardiol. 2011;34:395-400.

23. Danchin N, Marzilli M, Parkhomenko A, et al. Efficacy comparison of trimetazidine with therapeutic alternatives in stable angina pectoris: a network meta-analysis. Cardiology. 2011;120:59-72.

24. Zhao Y, Peng L, Luo Y, et al. Trimetazidine improves exercise tolerance in patients with 
ischemic heart disease: a meta-analysis. Herz. 2016;41:514-22.

25. Gao D, Ning N, Niu X, Hao G, Meng Z. Trimetazidine: a meta-analysis of randomised controlled trials in heart failure. Heart. 2011;97:278-86.

26. Zhang L, Lu Y, Jiang H, et al. Additional use of trimetazidine in patients with chronic heart failure: a meta-analysis. J Am Coll Cardiol. 2012;59:913-22.

27. Zhou $X$, Chen J. Is treatment with trimetazidine beneficial in patients with chronic heart failure? PLoS One. 2014;9:e94660.

28. Lopatin YM, Rosano GM, Fragasso G, et al. Rationale and benefits of trimetazidine by acting on cardiac metabolism in heart failure. Int J Cardiol. 2016;203:909-15.

29. Letter Campeau L. Grading of angina pectoris. Circulation. 1976;54:522-3.

30. Criteria Committee of the New York Heart Association. In: Nomenclature and criteria for diagnosis of diseases of the heart and great vessels, 9th ed. Boston: Little, Brown \& Co; 1994. p. 253-6.

31. Ferrari R, Ford I, Greenlaw N, et al. Geographical variations in the prevalence and management of cardiovascular risk factors in outpatients with CAD: data from the contemporary CLARIFY registry. Eur J Prevent Cardiol. 2015;22:1056-65.

32. Sellier P, Broustet JP. Assessment of anti-ischemic and antianginal effect at trough plasma concentration and safety of trimetazidine MR $35 \mathrm{mg}$ in patients with stable angina pectoris. A multicenter, double-blind, placebo-controlled study. Am J Cardiovasc Drugs. 2003;3:361-9.

33. Vitale C, Spoletini I, Malorni W, Perrone-Filardi P, Volterrani M, Rosano GM. Efficacy of trimetazidine on functional capacity in symptomatic patients with stable exertional angina-the VASCO-angina study. Int J Cardiol. 2013;168:1078-81.

34. Deng B, Huang SZ, Liu M, Li T, Lu Y. Combination therapy of trimetazidine with metoprolol in patients with stable angina pectoris. Chin J New Drugs Clin Rem. 2002;21:197-9.

35. Michaelides AP, Spiropoulos K, Dimopoulos K, Athanasiades D, Toutouzas P. Antianginal efficacy of the combination of trimetazidine-propranolol compared with isosorbide dinitrate-propranolol in patients with stable angina. Clin Drug Invest. 1997;13:8-14.

36. Nesukay EG. Treatment of stable angina in Ukraine: CLASSICA study. Ukr J Cardiol. 2014;2:43-7.

37. Marzilli M, Merz CN, Boden WE, et al. Obstructive coronary atherosclerosis and ischemic heart disease: an elusive link! J Am Coll Cardiol. 2012;60:951-6.

38. Fragasso G, Perseghin G, De Cobelli F, et al. Effects of metabolic modulation by trimetazidine on left ventricular function and phosphocreatine/adenosine triphosphate ratio in patients with heart failure. Eur Heart J. 2006;27:942-8. 